\title{
The Game Analysis Based on the Third-party Platform Supervision in
}

\section{E-commerce}

\author{
Jingzhi Zhou
}

School of Management Science and Engineering,Shandong Normal University,Jinan 250014,China Ozjz153@163.com

Keywords:E-commerce ,Game ,Trust,Suggestion

Abstract.The rapid development of the Internet varied the traditional trading approach and meanwhile gave rise to the Electrical Commerce.E-commerce in China has developed rapidly in recent years.Put forward the game analysis model on the third-party platform supervision and sellers in e-commerce as well as on the seller and buyer in e-commerce. And puts forward some Suggestions to solve problems.

\section{Introduction}

The e-commerce is facing a good opportunity to make great progress with the development of science and technology as well as the change of people's consumption consciousness[1].Especially in 2014, Alibaba and jingdong publics, 2015.11.11 taobao shopping carnival sales breakthrough in history,E-business has drawn people's attention again.But there are also many problems in e-commerce transactions, for example, physical objects in the online display can't actually touch, the product can't try it on, the seller's product quality and credit are affected products.Third-party platform is the result of the game about the consumers and sellers. The third-party platform is common in e-commerce.Headed by taobao, other platforms such as jingdong, dangdang, Su Ning, gome , Vipshop has allowed other tenants, also has the problem of the third party supervision. The third-party platform for sellers in e-commerce regulation more and more important.

\section{Game Analysis About the Sellers with the Third-party Platform Game Analysis in E-commerce}

In the electronic commerce information opaque, when to mislead consumers at a disadvantage, in e-commerce consumers to identify products sales in a more disadvantageous position relative to the entity[2].Consumers only by refusing to buy goods to punish the e-commerce sellers, so the third party platform should through regulation to limit the electronic commerce in the seller's dishonest behavior to ensure integrity in the deal.Third-party funds managed and the corresponding evaluation system to restrain the seller, a variety of methods to make up the defect that consumer can not effectively govern behavior in e-commerce sellers, however the seller enterprises will adopt various strategies to deal with the third party supervision.It is formed in the electronic commerce a game between the seller and the third- party platform.

The Basic Assumptions of the Model.(1)Game for two people , the participants of the game were a seller in the electronic commerce and a third party platform, and the game both sides in the sense of "rational economic man" is the pursuit of economic benefit maximization.In e-commerce the sellers to pursue its own profit maximization, the third-party platform to pursue the benefit maximization of the whole society except for the seller.

(2)The information is complete, that is, the seller and the third party supervision platform under different combination of the strategy profit are known to each other. 
(3)Game is static, although the seller and the third party supervision platform is not at the same time to make a decision , but they are no one can get the opponent's strategy before making a decision .

(4) In the game, the strategy of sellers is to sell high quality products or shoddy products, the third party platform strategy for regulation, or no regulation[4,5].

Establishment and Analysis of the Model.Assume that U1 indicates the profits of sellers selling advantage, U2 said sell inferior product profit, U1 > U2;Sellers sell high quality products the benefit of the whole society as S1, sell inferior products the benefit of the whole society to S2, S1 > S2; If the seller sell inferior products, at the same time, it was the third party supervision station found, and the fine, fine for $\mathrm{F}[3]$.

Table 1 In the electronic commerce between the seller and e-commerce platform game payoff

\begin{tabular}{|l|l|l|}
\multicolumn{3}{|c|}{ matrix } \\
\hline the third-party platform & The seller & inferior products \\
\hline & quality product & S2+F-C, U2-F \\
\hline supervise & S1-C, U1 & S2, U2 \\
\hline Without supervision & S1, U1 \\
\hline
\end{tabular}

For the third party supervision platform strategy are analyzed.If e-commerce sellers choose the production of high quality product strategy, then choose the optimal strategy of third party supervision platform is not regulated, because S1 > S1 - C; If the sellers choose inferior products in electronic commerce strategy, the third party supervision platform consider comparing $\mathrm{F}$ and $\mathrm{C}$ whether to choose the size of the regulation.

If $\mathrm{F}<\mathrm{C}$, at this point the third-party platform supervision cost is greater than the third party supervision platform to produce inferior products in e-commerce sellers penalty, the third-party platform supervision the best strategy is not regulated.In e-commerce sellers choose inferior products at the same time, the third party supervision platform will still choose not to regulation, so the third party supervision platform of dominant strategy is not regulation strictly.For sellers in electronic commerce, it from a rational perspective, the information is complete, the electronic commerce in the seller completely know the third-party platform supervision will choose not to supervision, so it will choose produced shoddy goods.So (without regulation, bad products) will be the equilibrium solution;If $\mathrm{F}>\mathrm{C}$, the third party supervision platform of regulatory supervision platform of the regulatory costs less than a third party in the production of bad products in e-commerce sellers penalty, third-party platform is the optimal strategy of overseeing regulation, so the third party supervision platform in order to make the electronic commerce in the production of high quality products, the seller will have to strengthen the regulatory penalties.

To analyze electronic commerce in the seller's strategy.Choose not to regulation, if the third party supervision platform with U2 > U1, the electronic commerce in the seller's optimal strategy must be produced shoddy goods; If the third party supervision platform choice regulation, in this case, the electronic commerce in the seller would compare to the U1 and U2.When U1 < U2 - F, F < U2 - U1, the electronic commerce in the seller's optimal choice is to produce inferior products, and therefore inferior product becomes the electronic commerce in the seller's strict optimal strategy.When U1 > U2 - F, F > U2 - U1, the electronic commerce in the seller's optimal choice is to produce high quality products.

Through the above analysis of the strategy can be found, to ensure that the electronic commerce in the production of high quality products, the seller must make F > C and F > U2 - U1.Obviously, the game there is no pure strategy Nash equilibrium, but a mixed strategy Nash equilibrium.Assuming that the third party supervision platform based on the choice probability $\mathrm{P}$ supervision, probability of 1 - P is not supervision;In e-commerce sellers to probability q select 
production high quality product, the probability of 1 - q produced shoddy goods.The assuming show that :

$$
\begin{aligned}
& (S 1-C) q+(S 2+F-C)(1-q)=S 1 q+S 2(1-q) \\
& U 1 p+U 1(1-P)=(U 2-F) P+U 2(1-P)
\end{aligned}
$$

The solution by equation (1): $\mathrm{q}=1-\mathrm{C} / \mathrm{F}$.

The solution by equation (2): $\mathrm{P}=(\mathrm{U} 2-\mathrm{U} 1) / \mathrm{F}$.

Can be mixed strategy Nash equilibrium :((U2 - U1)/F, 1 - (U2 - U1)/F);(q = 1 - C/F, C/F).

By q $=1-\mathrm{C} / \mathrm{F}$, in e-commerce sellers choose to produce high quality product strategy or choose inferior product strategy is closely related to monitor cost and fine lines.If the fine is fixed, the third party supervision platform supervision cost is higher, in e-commerce sellers choose the greater the probability of inferior products.If the fixed supervision cost, fine lines, the greater the probability of e-commerce sellers in the production of bad products will be smaller.

\section{The Game Analysis about of the Seller and the Buyer in Electronic Commerce}

In the traditional product quality supervision system, the consumer is always in the edge position.However, which is dominated by the third party platform in e-commerce sellers product regulation is never lack of the participation of the consumer.Because the consumer is the product quality risk takers, must be qualified to supervise in e-commerce sellers.Therefore, sellers and consumers in the e-commerce this direct interaction is also a kind of game.

The Basic Assumptions of the Model.(1)Game players have two of the participants in the game, respectively in e-commerce sellers and consumers, and the game both sides is the economy in the sense of "rational economic man", is the pursuit of benefit maximization, the electronic commerce in the seller's production behavior, consumer behavior is the result of its own choice.

(2) The information is complete, the electronic commerce of the seller and the consumer benefit under different combination of the strategy are known to each other.

(3) Game is static, in their both sides before making a decision no one can get each other strategy.

Establishment and Analysis of the Model. Assume that electronic commerce in the seller's strategy is to produce high quality products or shoddy products, consumer's strategy is to buy or not to buy.When e-commerce sellers in the production of quality products, if consumers choose to buy, in e-commerce sellers and consumers benefit from $\mathrm{m} 1$, respectively, c; If consumers choose not to buy, in e-commerce sellers and consumers benefit respectively - $\mathrm{n} 1,0$. When sellers produce inferior products in electronic commerce, if consumers choose to buy, then in e-commerce sellers and consumers benefit of $\mathrm{m} 2$, respectively - g; If consumers choose not to buy, in e-commerce sellers and consumers benefit respectively - n2, 0.Under the condition of asymmetric information, electronic commerce between seller and consumers in the payoff matrix as shown in table.

Table 2 In e-commerce game payoff matrix between the seller and consumers

\begin{tabular}{|l|l|l|}
\hline consumers & seller \\
\hline & quality products & inferior products \\
\hline to buy & c,m1 & -g,m2 \\
\hline not to buy & $0,-\mathrm{n} 1$ & $0,-\mathrm{n} 2$ \\
\hline
\end{tabular}

Due to the high quality products and bad products will be sold at the same price, and the 
production cost is higher than that of inferior product, so the electronic commerce by the seller in the production of quality products to get yields higher than produced shoddy goods, if the product meet sales dilemma, the damage is greater.Therefore, the above hypothesis have $\mathrm{m} 2>\mathrm{m} 1>0, \mathrm{n} 1>$ $\mathrm{n} 2>0, \mathrm{c}>0, \mathrm{~g}>0$. Because of information opaque, consumers whether sellers in the production of quality products in electronic commerce strategy can not be sure.But in this case, due to the seller in the production of high quality products to benefit from e-commerce for $\mathrm{m} 1$, produce inferior product benefit for $\mathrm{m} 2, \mathrm{~m} 2>\mathrm{m} 1>0, \mathrm{~m} 1$ and $\mathrm{m} 2$ for the rational consumer, they predict the sellers make use of information asymmetry in e-commerce to produce inferior products, so consumers to choose the best strategy for not to purchase at this time.And rational seller know that consumers will not buy their products, produce inferior product becomes the electronic commerce in the seller's strict optimal strategy.(not to buy, produce inferior products), become the consumers and sellers in e-commerce Nash equilibrium, at this time, the game got caught up in the "prisoner's dilemma".Because both parties from their respective interests to choose their own strategy, finally both sides failed to achieve their own interests, caused great harm to the industry and society.

In e-commerce, of course, sellers and consumers have interests of all time.In the reality of online consumption, e-commerce sellers and consumers in the game is repeated game many times.In e-commerce sellers starting from the production of quality products, continue to produce quality products; If the last time the production of inferior products, continue to produce inferior products.For consumers, when the first consumers choose to buy, as long as the seller never produce inferior products in electronic commerce, then consumers will choose to continue to buy; If the seller in the electronic commerce once produce inferior products, consumers will no longer choose after purchase.Equilibrium is the result of the (purchase, production quality products).Therefore, for consumers and sellers in e-commerce (purchase, production quality products) strategy is the best choice.

\section{Conclusions and Recommendations}

Through the analysis of the above two static game model, we can draw the following conclusion: in order to solve China's e-commerce sellers in the product quality and safety supervision, first to the third party supervision platform, it must increase to produce inferior products electronic commerce in the seller's supervision and punishment, and the penalties must be better than regulatory costs and e-commerce sellers in the production of inferior product profit.Third party supervision platform to try to reduce regulatory costs, avoid unnecessary consumption.Also to encourage consumers to participate in the e-commerce in the seller's product quality supervision, resolutely resist the inferior products, stop in e-commerce sellers continue to produce inferior products, let the electronic commerce in the seller know the inferior products will not be able to survive in e-commerce sellers market[6].

According to the above conclusions, the paper puts forward the following help to solve the quality problem in China's e-commerce.

Increase the Penalties.Analysis can be seen from the above model, when selling inferior products increased penalties, sellers violate compasses costs will increase, consider not the good faith between the benefits and will face punishment cost problem.Dishonest profits cannot make up for the loss.This will force the good faith management, an operator can have the effect of regulation.

In E-commerce Operators to the Public.E-commerce itself and entities on perceived can touch sex is very different, but in e-commerce due to the seller's review is also lower than the same industry with the size of the entity management, makes the seller cheat cost is cheaper in the entity management, cause deception frequent phenomenon in e-commerce transactions. 
Improve the System of Credit Evaluation.Is common in the present e-commerce brush the phenomenon of credit, the seller's credit is when customers buy more attention, because of the existence of brush credit mislead consumers, also caused adverse to other businesses.Thus improve the system of credit evaluation can supervise and urge the seller the good faith management, correctly guide the consumer shopping.

Enhance the Communication Between the Third-party Platform with Sellers.Buyers in the problems in the electronic commerce can timely supervision platform to communicate with a third party, the problem timely feedback to a third party, the third party in a timely manner to master the seller information, communication and problem solving, situation and give corresponding punishment measures.

\section{References}

[1]Li Wei-An,Wu De-Sheng,Xu Hao(2007).Reputation in China's online auction market:Evidence from the Taobao website,Nankai Business Review,10(5):36-46.

[2]Gan Z B,Li Y J,Xiao GQ et al(2008).A novel reputation model for mobile agent-based e-commerce systems//proceedings of the 2nd International Conference on Information Security and Assurance,Hanwha Resort Haeundae.Busan,Korea:253-260.

[3]Hongbo(2009).The Behavior Tendency and Game Relation about Protectors of Cultivated Land Resource Security in China . China Population, Resources and Environment, 19(1) : 82 - 87.

[4]Algaba E, Bilbao JM, Fernandez JR, Jimenez A (2004) The Lovsz extension of market games. Theory Decis 56:229-23.

[5]Nowak AS (2010) On a noncooperative stochastic game played by internally cooperating generations. J Optim Theory Appl 144(1):88-106.

[6]Lim, Ch., Bearden, J. N., \& Smith, J. C. (2006). Sequential search with multiatribute options. Decision Analysis, 3(1), 3-15. 